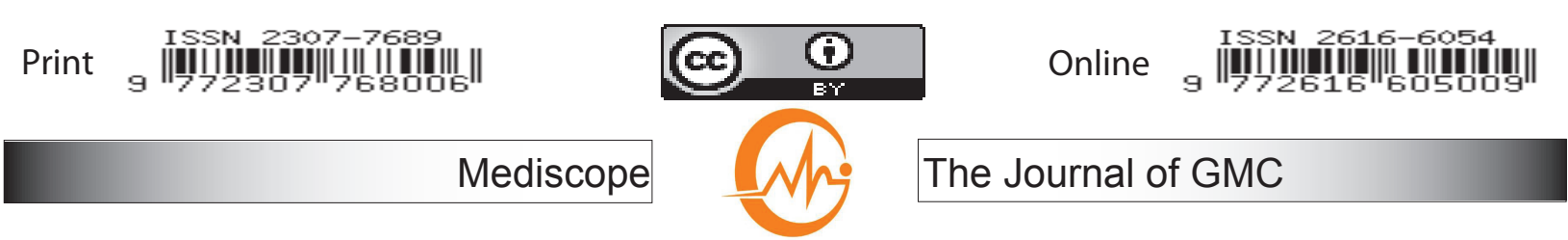

\title{
Neonatal Outcome in Meconium Stained Amniotic Fluid (MSAF): A Study in a Neonatal High Dependency Unit (NHDU) of a Medical College Hospital
}

\author{
MB Ali ${ }^{1}$, AA Maruf², N Naher ${ }^{3}, \mathrm{~S}$ Islam ${ }^{4}$
}

\begin{abstract}
Background: Meconium-stained amniotic fluid (MSAF) is a potential sign of fetal hypoxia as well as a potential toxin if the fetus aspirates with a gasping breath in utero or when it takes its first breaths following birth. Objective: To evaluate the outcome of neonates with meconium-stained amniotic fluid (MSAF). Material and Methods: This prospective observational study was carried out in the department of pediatrics of Gazi medical college Hospital, Khulna during one calendar year from 01 July 2016 to 30 June 2017. Maternal risk factors for MSAF, modes of delivery of neonates were recorded. All neonates born with MSAF were included in this study: they were shifted to neonatal high dependency unit for observation and monitoring as per the pediatrician's advice. Neonatal outcomes like birth asphyxia, neonatal jaundice, aspiration pneumonia, septicemia, meconium aspiration syndrome (MAS), hypoxic-ischemic encephalopathy (HIE) and death were observed and recorded. Result: A total of 157 babies were included during the study period. Modes of delivery of babies were: normal delivery $86(54.78 \%)$, caesarean section $48(30.57 \%)$ and instrumental delivery $23(14.65 \%)$. Maternal risk factors were postdated pregnancy $51(32.48 \%)$, previous caesarian section $20(12.74 \%)$, pregnancy-induced hypertension (PIH) $20(12.74 \%)$, premature rupture of membranes $18(11.46 \%)$, gestational diabetes mellitus (GDM) $17(10.83 \%)$, intrauterine growth retardation (IUGR) 14 (8.92\%), cephalopelvic disproportion $9(5.73 \%)$ and anemia $8(5.10 \%)$. Outcome of babies were: $118(75.16 \%)$ babies were discharged without any complications, 10(6.37\%) developed neonatal jaundice, 10(6.37\%) meconium aspiration syndrome (MAS), 8(5.10\%) birth asphyxia, 4(2.55\%), aspiration pneumonia, 3(1.91\%) hypoxic-ischemic encephalopathy (HIE), $2(1.27 \%$ ) septicemia and $2(1.27 \%)$ baby died in early neonatal period.
\end{abstract}

Keywords: Meconium-stained amniotic fluid (MSAF), neonate, birth asphyxia, meconium aspiration syndrome.

\section{Introduction:}

Meconium is named according to Greek literature "mekonionarion" - "opium-like" as said by Aristotle in reference to its tarries like appearance and a belief that it induces sleep in the fetus. ${ }^{1}$ The passage of meconium into the amniotic fluid during labor (fresh meconium) is one of the traditional indicators of

1. MB Ali, MBBS, DCH, FPCC, Associate Professor, Department of Paediatrics, Gazi Medical College, Khulna. Email: drbarkot.ch@gmail.com

2. AA Maruf, MBBS, FCPS (Anaesthesiology), Border Guard Hospital, Dhaka.

3. N Naher, MBBS, DGO, Assistant Professor, Department of Gynaecology \& Obstetrics, GMC, Khulna.

4. S Islam, MBBS, Registrar, Department of Paediatrics, Gazi Medical College, Khulna. 
fetal distress and is associated with increased fetal morbidity and mortality. ${ }^{2}$ Meconiumstained amniotic fluid (MSAF) is known to be associated with several maternal and neonatal risk factors. ${ }^{3}$ In healthy, well-oxygenated fetuses, meconium is cleared from the lungs by the normal physiological mechanism. Most of them can develop an effective breathing movement to signs of aspiration and persistent hypoxia. ${ }^{4}$

MSAF is considered a harbinger of fetal compromise because of its direct correlation with fetal distress and increased likelihood of aspiration of meconium with resultant deleterious effects on the neonatal lung. ${ }^{5}$ Meconium passage is rare before 34 weeks of gestations and after 37 weeks its incidence increases steadily with increasing gestational age. ${ }^{6}$ Passage of meconium in utero with staining of amniotic fluid occurs in $12 \%$ to $16 \%$ of all deliveries. ${ }^{7-10}$ Presence of meconium below the vocal cord is known as meconium aspiration and this finding occurs in $20 \%$ to $30 \%$ of all infants with MSAF fluid with around $12 \%$ mortality. 8,10

Aspiration can occur in utero with fetal gasping or after birth with the first breath of life. ${ }^{11}$ As meconium stained amniotic fluid is associated with lots of adverse outcome of the fetus and has long been considered to be a bad predictor of fetal outcome and as there is no significant data in our country, so this observational study was undertaken to find out immediate fetal outcome with meconium stained amniotic fluid.

\section{Materials and Methods}

This is a prospective observational study carried out at the department of pediatrics of Gazi Medical College Hospital, Khulna during one Calendar year from 01 July 2016 to 30 June 2017. A total of 157 Patients with meconium-stained amniotic fluid during labor were studied.

\section{Inclusion criteria:}

1. Patients with $>37$ weeks of gestational age and presenting with meconium- stained amniotic fluid.

2. Patients with meconium-stained amniotic fluid and cephalic presentation.

3. Patients presenting with meconiumstained amniotic fluid after spontaneous or artificial rupture of membrane

\section{Exclusion criteria:}

1. Patients with other than cephalic presentation.

2. Patients with clear liquor after spontaneous or artificial rupture of membrane.

3. Preterm, intrauterine death, congenital anomalies, multiple pregnancies and the non-cooperative patients who refused to give their consent for the participation in the study.

Detailed maternal history was noted and delivery of the baby such as the normal, instrumental or caesarean section was attended by a pediatrician to record perinatal events in association with obstetricians. All babies thus born with MSAF were shifted to neonatal high dependency unit for observation and monitoring as per the pediatrician's advice.

Following fetal outcomes were observed and recorded:

1. Birth asphyxia: gasping or ineffective breathing or lack of breathing at one minute of life.

2. Neonatal jaundice: assessing of serum bilirubin level along with G6PD estimation in case of male babies.

3. Aspiration pneumonia: inflammation of the lungs due to aspiration.

4. Septicemia: diagnosed on clinical grounds along with positive blood culture.

5. Meconium aspiration syndrome: diagnostic criteria were:

a. History of meconium-stained amniotic fluid.

b. Evidence of respiratory distress like tachypnea, subcostal, and intercostal retractions, grunting. 
c. Chest $\mathrm{x}$-ray showing bilateral asymmetric patchy infiltrates.

6. Hypoxic ischemic encephalopathy (HIE): Damage of cells in the central nervous system (the brain and spinal cord) from inadequate oxygen.

7. Early neonatal death.

Data were collected, compiled and entered in a spreadsheet (Microsoft Excel; Microsoft Corporation) and analyzed using appropriate statistical tools. Results were expressed as a percentage (\%).

\section{Results}

A total of 157 babies were included during the study period. Modes of delivery of babies are shown in figure 1 . Among them $86(54.78 \%)$ were born by normal delivery, $48(30.57 \%)$ by caesarean section and $23(14.65 \%)$ by instrumental delivery. Sex distribution is shown in figure 2. $77(49.05 \%)$ were males and $80(50.95 \%)$ were females. Maternal risk factors are shown in table 1. Risk factors were postdated pregnancy $51(32.48 \%)$, previous caesarian section 20(12.74\%), pregnancy-induced hypertension (PIH) $20(12.74 \%)$, premature rupture of membranes 18(11.46\%), gestational diabetes mellitus (GDM) 17(10.83\%), intrauterine growth retardation (IUGR) 14 (8.92\%), cephalopelvic disproportion $9(5.73 \%)$ and anemia $8(5.10 \%)$. The outcome of neonates is shown in Table 2. Among them $118(75.16 \%)$ babies were discharged without any complications, $10(6.37 \%)$ developed neonatal jaundice, 10(6.37\%) meconium aspiration syndrome (MAS), 8(5.10\%) birth asphyxia, 4(2.55\%), aspiration pneumonia, $3(1.91 \%)$ hypoxic-ischemic encephalopathy (HIE), 2(1.27\%) septicemia and 2(1.27\%) baby died in early neonatal period.

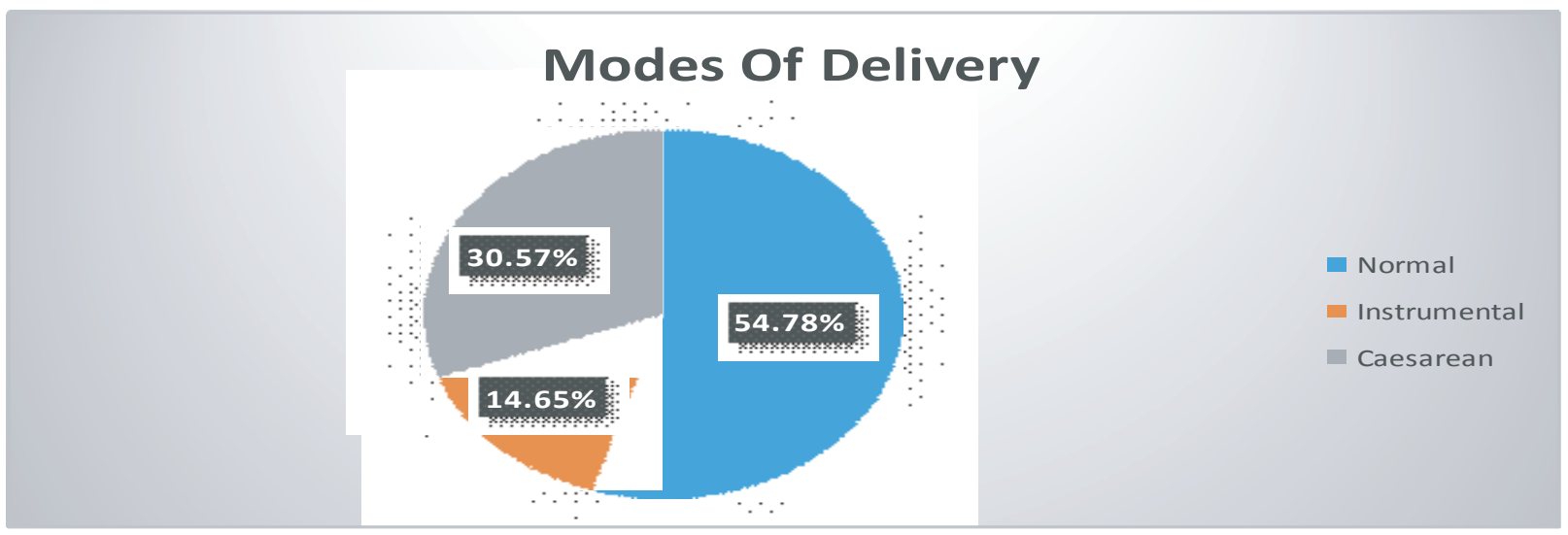

Fig 1: Modes of delivery of babies

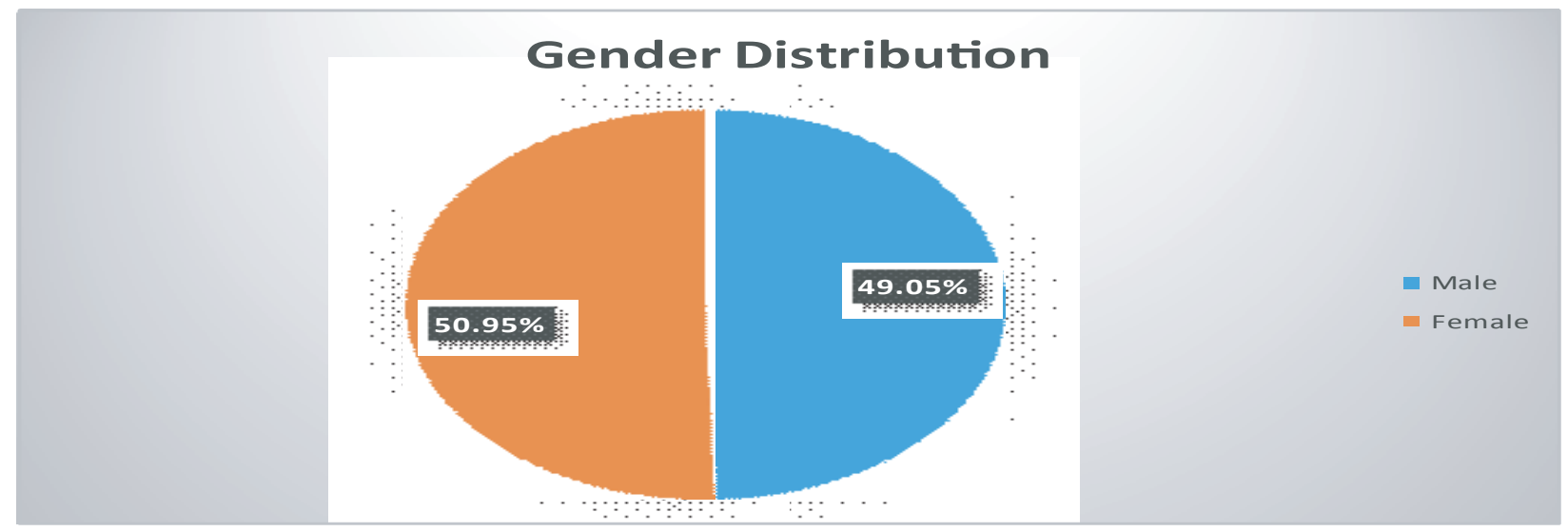

Fig 2: Gender Distribution among neonates 
Table 1: Maternal Risk Factors

\begin{tabular}{|l|c|c|}
\hline Risk Factors & Number & Percentage \\
\hline Postdated Pregnancy & 51 & $32.48 \%$ \\
\hline Pregnancy-induced hypertension (PIH) & 20 & $12.74 \%$ \\
\hline Previous Caesarian Section & 20 & $12.74 \%$ \\
\hline Premature rupture of membranes & 18 & $11.46 \%$ \\
\hline Gestational diabetes mellitus (GDM) & 17 & $10.83 \%$ \\
\hline Intrauterine growth retardation (IUGR) & 14 & $8.92 \%$ \\
\hline Cephalopelvic Disproportion & 9 & $5.73 \%$ \\
\hline Anemia & 8 & $5.10 \%$ \\
\hline Total & $\mathbf{1 5 7}$ & $\mathbf{1 0 0 \%}$ \\
\hline
\end{tabular}

Table 2: Outcome of Neonates

\begin{tabular}{|l|c|c|}
\hline Outcome of neonates & Number & Percentage \\
\hline Discharged without any complications & 118 & $75.16 \%$ \\
\hline Neonatal Jaundice & 10 & $6.37 \%$ \\
\hline Meconium Aspiration Syndrome & 10 & $6.37 \%$ \\
\hline Birth asphyxia & 8 & $5.10 \%$ \\
\hline Aspiration Pneumonia & 4 & $2.55 \%$ \\
\hline Hypoxic ischemic encephalopathy (HIE) & 3 & $1.91 \%$ \\
\hline Septicemia & 2 & $1.27 \%$ \\
\hline Early Neonatal Death & 2 & $1.27 \%$ \\
\hline \multicolumn{1}{|c|}{ Total } & $\mathbf{1 5 7}$ & $\mathbf{1 0 0 \%}$ \\
\hline
\end{tabular}

\section{Discussion}

A fetal condition during labor is usually assessed by fetal heart rate and checking the presence of meconium in the amniotic fluid. ${ }^{12,13}$ The MSAF and its associations are still very important determinants of perinatal morbidity and mortality, and a successful management of such pregnancies is possible only after a better understanding of the pathophysiology of the meconium passage. The passage of meconium may be a normal physiological event reflecting fetal maturity. It may, on the other hand, reflect fetal hypoxia or increased vagal activity from cord compression. ${ }^{14}$ The detection of MSAF during labor often causes apprehension and anxiety for the patient as well as for the health provider as it is often considered an indication of fetal distress. ${ }^{15}$ The exact reason for the passage of meconium in the amniotic fluid is poorly understood. It could reflect the state of compensated fetal distress as it is suggested by a few babies who are actually acidotic during labor. ${ }^{16}$ Acute or chronic fetal hypoxia can result in the passage of meconium in utero. ${ }^{17}$

The frequency of MSAF increased with advanced gestational age at delivery independent of the presence or absence of labor. ${ }^{18}$ In present study 51(32.48\%) patients had advanced gestational age suggestive of a significant association of postdate pregnancy with meconium. Naveen $S$ et al. ${ }^{19}$ conducted a study on 1500 deliveries to identify predictors of MSAF in India and they observed that a postdated pregnancy was one of the risk factors for MSAF, Pregnancyinduced hypertension (PIH) was associated with MSAF, the incidence in this study was $20(12.74 \%)$ which is almost similar to the incidence of $13 \%$ in studies of Bhide et al. ${ }^{20}$ and Hosne Ara Khatun et al. ${ }^{21}$ Association of $\mathrm{PIH}$ with MSAF is caused by an underlying uteroplacental insufficiency, which causes fetal hypoxia, resulting in meconium passage. Premature rupture of membrane (PROM) is a well -risk factor for intrauterine infection. ${ }^{22}$ 
Several investigators have suggested that MSAF is highly associated with infection, including endometritis and chorioamnionitis. $^{23}$ In present study 18 (11.46\%) patients with PROM with MSAF which is a significant association. The longer the duration of labor, the higher the risk of MSAF in term singleton gestation. ${ }^{18}$ In this study $9(5.73 \%)$ patients with cephalopelvic disproportions and many had been given a vigorous trial and were referred with the prolonged second stage of dystocia.

In the present study 86(54.78\%) patients delivered through normal vaginal delivery, $48(30.57 \%)$ delivered by LUCS and $23(14.65 \%)$ patients had instrumental delivery. Saunders et al. ${ }^{24}$ reported that caesarean sections were performed twice as frequently in subjects with meconium-stained amniotic fluid. Wong $\mathrm{SF}^{25}$ found that $13.2 \%$ of MSAF had undergone cesarean sections as compared to $8.8 \%$ cases who had undergone them in clear amniotic fluid. In the present study, $118(75.16 \%)$ of babies remained asymptomatic and required only routine care at birth. Of the other 39 babies needing care in neonatal high dependency unit (NHDU), $10(6.37 \%)$ developed neonatal jaundice, $10(6.37 \%)$ meconium aspiration syndrome (MAS), 8(5.10\%) birth asphyxia, 4(2.55\%), aspiration pneumonia, 3(1.91\%) hypoxicischemic encephalopathy (HIE), 2(1.27\%) septicemia and $2(1.27 \%)$ baby died in early neonatal period. Ashtekar $S$ et al. ${ }^{26}$ in their study concluded that birth asphyxia (42\%), sepsis $(23.2 \%)$, and jaundice $(23.2 \%)$ and others $(7.8 \%)$ including intraventricular hemorrhage and necrotizing enterocolitis were complications seen in neonates born with MSAF. Kumari $\mathrm{R}$ et al. ${ }^{27}$ in her study found $63(84.0 \%)$ were asymptomatic and $1(1.3 \%)$ had birth Asphyxia. Khazardoost et al. ${ }^{28}$ observed $64(21.1 \%)$ neonates with meconium aspiration syndrome. Espinheria $\mathrm{MC}$ et al. ${ }^{29}$ reported $1.4 \%$ of $\mathrm{NICU}$ admission of which $43.1 \%$ needed ventilator support and
$5 \%$ had meconium aspiration syndrome. Patil et al. ${ }^{30}$ reported meconium aspiration was the cause of death in around 4 cases and one died due to serve birth asphyxia with hypoxic-ischemic encephalopathy. Gurmeet Singh $^{31}$ found $16 \%$ mortality with MSAF.

\section{Conclusion}

MSAF is really worrisome for both obstetrician and pediatrician point of view as it increases the caesarean rates, causes birth asphyxia, meconium aspiration syndrome and increases neonatal intensive care unit admissions. Close monitoring of all neonates born with MSAF is required and such babies are to be kept under observation in a proper neonatal care setting. Early intervention might lead to a reduction in the neonatal adverse outcome to reduce morbidity and mortality.

\section{References:}

1. Jalal M, Abu Shwaeesh. Diseases of Respiratory system. In: Fanaroff's and martin's Neonatal perinatal Medicine diseases of the fetus and Infant 8th edn. Saunders: Elsevier; 2006; 134,563-565.

2. Anne Greenough, Anthony D Milnerpulmonary Diseases of New-born.in: Robert's textbook of neonatology 4th edn. Cruchill living stone; 2006;:199,502-508.

3. Mohamad Reza Sedaghatian, Leena Othman, Nadirea Rashid, Pallath Ramachandran, Abdul Bari Bener. An 8year study of meconium Stained amniotic fluid in different Ethnic groups. Kuwait medical journal 2004; 36:266-269.

4. Keenan W, Recommendations for management of the child born through meconium stained amniotic fluid. Pediatrics 2004;113:133-134.

5. Nizami SQ, Arif MA. Respiratory distress syndrome among hospital born infants. Pak paediatr j 1985 ;9:276-282. 
6. Wiswell TA, Bent RC. Meconium staining and the meconium aspiration syndrome, unresolved issues. In pediatric clinics of North America updates on Neonatology 1993;40:955-981.

7. Brown BL, Gleicher N. Intrauterine meconium aspiration. Obstet Gynecol 1981;52:26-9

8. Cochran WG. Sampling techniques. 3rd ed. New York. John willey and sons $177 ; 81$.

9. Orimadegun $\mathrm{AE}$, Akinbami Fo, Tongo OO,Okereke Jo. Comparison of neonates born outside and insde hospitals in a children emergency unit, southwest of Ngeria. Pediatr Emerg Care 2008 ; 24:354-358.

10. Owa JA, Osinaike Al. Neonatal Morbidity and mortality Nigeria. Indian $\mathrm{J}$ pediatr 1998;65:441-449.

11. Roy Rn, Nandy 5, Shrivastava p , Chakraborty A, Das gupta M, kundu TK. Morality pattern of hospitallzed Children in a tertiary care hospital of Kolkata .Indian J Community Med 2008;33:187-189.

12. Nice, intrapartum guideline 55 , London : national institutefor health and clinical excellence 2007.

13. Gee H Routin interrpartum care: an over vew. In: Luesley dm, Barker pn Obstetrics and gynecology : an evidence based test for MRCOG, 2nd edition.Hodder Arnoid 2010:287-295.

14. Ahanya sn, Lakshmanan J Morgan DL, Ross MG. Meconium passage in utro: mechanism consequences and management. Obstet gynecological surv 2004;60:45-56.

15. Naqvi sb ,Manzor s. Association of MSAF with perinatal outcome in pregnant women of 37-42 weeks gestation. Pak J Surg 2011;27(4):292-298.

16. Abramovici $\mathrm{H}$, Brandes JM, Fuchs $\mathrm{K}$, Timor - Tritsch 1. Meconium during delivery assign of compensated fetal distress. AmJ obstetet gynecol 1974:118; 215-255.

17. Stark A Meconium aspiration. Manual of neonatal care 2003; 5:402-403.
18. Kale.SM HJ yang, CW park, S Mzaki tuvi, Bhy yoon and $\mathrm{R}$ Romero. The frequency of meconium- stained amniotic fluid increases as a funcation of the duration of labor. J Matern Fetal Neonatal Med 2011;24(70:880-885.

19. Naveen 5 , kumar SV,RITU S, Kushia p. predictors of meconium stained amniotic flu id: apo0ssible strategy to reduc neonatal morbidity and mortality. J obstet Gynecol indian 2006;56:514-517.

20. Bhide ss, shendurnikar N,Alyer s, Baxi SR. Neonatal outcome after meconium stained amniotic fluid. J obstet Gynecol indian 1993; 44:933-935.

21. Khatun M, Arzu J, Haque E, kamal MAL.Mamin M, Khan M, KhanM et al. Fetal outcome in Deliveries with Meconium stained Liquor. Bangladesh $\mathrm{J}$ child Health 2009; 33:41-45.

22. Burstein E, Sheiner E,Mazor M, carmel E, levy $A$, hershkovitz $R$. Indentfying risk factors for premature rupture of membranes in small for gestational age neonates: a population based study. J Matern Fetal Neonatal Med 2008; 21:816-820.

23. Rao S, paviova Z, Incerpi MH, Pamannathan R. Meconiumstained amniotic fluid and neonatal morbidity in near term and term deliveries with acute histologic chorioamnionitis and/or funisitis. Perinatal 2001;21:537-540.

24. Saunder s K. Should we worry about meconium ? Controlled Study of neonatal outcome. Trop Doct 2002;32(1):7-10.

25. Wrong SF,Chow KM,Ho LC. The relative risk fetal distress in pregnancy associated with meconium -stained liquor at different gestation .journal of Obstetrics and Gynecol 2002;22(6):594-599.

26. Ashtekar Sd, Galkwad Rsnk. Clinical study of meconium aspiration syndrome in relation to birth weight and gestational maturity at genarel hospital sangli. Internat Med J 2014; 1(5):189-192.

27. KUmari R, Srichand p, Devrajani BR, Shan Sz,Devrajani T,Blbi I and Kumar R. Foetal outcome in patient with meconium stained liquor. J pak med assoc 2012; 
62(50;474-476.

28. Khazardoost S,Hantoushzadeh S, khooshideh $\mathrm{M}$ and borna S.Risk factors for Ma in MSAF. J obstet gynaecol 2007; 27(6):577-579.

29. Espinheira MC Grilo M Rocha G, Guedes $B$ and Guimaraes $H$, Meconium aspiration syndrome-The experience of a tertiary centre. Rev Portal pneumol 2011; 17(2):71-76.
30. Patil KP, Swamy MK, Samatha K. A one year cross sectional study of management practices of meconium stained amniotic fluid and perinatal outcome Obstet Gynecol India 2006;56:128-130.

31. Gurmeet Singh, Onkar Singh, Karuna Thapar Neonatal outcome in meconium stained amniotic fluid: a hospital based study. Int J Contemp Pediatr 2017; 4(2): 356-360. 